\title{
Metastasis-directed therapy for oligometastatic urological tumours: still no second-hand news
}

\author{
Charlien Berghen ${ }^{1}$, Steven Joniau ${ }^{2}$, Christof Vulsteke ${ }^{3,4}$, Maarten Albersen², Gaëtan Devos ${ }^{2}$, Kato Rans ${ }^{1}$, Karin Haustermans ${ }^{1}$ and \\ Gert De Meerleer ${ }^{1}$ \\ ${ }^{1}$ Department of Radiation Oncology, Leuven University Hospital, Leuven, Belgium \\ ${ }^{2}$ Department of Urology, Leuven University Hospital, Leuven, Belgium \\ ${ }^{3}$ Department of Oncology, Ghent Maria Middelares Hospital, Ghent, Belgium \\ ${ }^{4}$ Department of Molecular Imaging, Pathology, Radiotherapy and Oncology (MIPRO), Center for Oncological Research (CORE), University of Antwerp, \\ Antwerp, Belgium
}

\begin{abstract}
For patients presenting with limited metastatic disease burden, known as the oligometastatic state of disease, a more aggressive treatment approach targeting the new or progressive metastatic lesions might improve patient outcome, with no or only limited toxicity to be expected from the treatment. This review provides an overview of the existing evidence and on-going trials on oligometastatic disease and metastasis-directed therapy in the field of renal, bladder and prostate cancer.
\end{abstract}

Keywords: oligometastases, urological tumours, prostate cancer, bladder cancer, renal cancer, radiotherapy, metastasectomy

\section{Introduction}

The perspective on metastatic disease has changed dramatically, due to the availability of novel imaging modalities as well as molecular diagnostics and further improvement of available treatments. From a dichotomy between localised and metastatic disease towards the concept of a sequence of events acquiring metastatic ability [1], limited cancer spread is now seen as a transitional state between locally confined disease and widespread metastases. This state is called the oligometastatic state of disease [2], defined as the presence of limited metastatic lesions up to three or five [3, 4]. There are three general definitions of oligometastatic disease, implicating different treatment approaches and therapeutic goals [5]. In upfront oligometastatic disease (synchronous metastasis), the disease has spread to limited sites and these metastases are present at diagnosis, i.e., before initiation of any treatment. In case of oligorecurrent metastatic disease (metachronous metastases), a limited number of metastases will develop some time after treatment with curative intent of the primary tumour. Oligoprogression is defined as the appearance
Correspondence to: Charlien Berghen Email: charlien.berghen@uzleuven.be

ecancer 2020, 14:1036

https://doi.org/10.3332/ecancer.2020.1036

Published: 07/05/2020

Received: $27 / 11 / 2019$

Publication costs for this article were supported by ecancer (UK Charity number 1176307).

Copyright: ( $)$ the authors; licensee ecancermedicalscience. This is an Open Access article distributed under the terms of the Creative Commons Attribution License (http:// creativecommons.org/licenses/by/3.0), which permits unrestricted use, distribution, and reproduction in any medium, provided the original work is properly cited. 
and/or progression of a limited number of lesions in a metastatic patient, while all other lesions are being controlled by on-going systemic treatment.

Traditionally, systemic treatment is considered as the standard treatment for the majority of patients with metastatic cancer [6], including various treatment types ranging from chemotherapy to hormonal treatment and/or immunotherapy. In the past, diagnosis of metastatic disease ruled out any chance for cure, and patients would eventually succumb to their disease. More recently, it has been thought that cure might not be so unrealistic as first thought, at least for a subgroup of patients, as CheckMate 214 showed $10.5 \%$ complete responses with immune checkpoint inhibitors (ICl) in metastatic renal cell carcinoma (mRCC) patients, of which the majority ongoing after 30 months [7]. Furthermore, opposed to polymetastatic patients, oligometastatic patients have a more indolent disease course [2]. As a consequence, a different treatment strategy, called metastasis-directed therapy (MDT), has been developed. The rationale behind MDT is that the eradication of a low number of metastatic sites will hamper further metastatic dissemination, as it has been clearly demonstrated that metastases are an important source of further metastatic spread [8]. Reducing further metastatic spread by MDT might improve progression-free survival and overall survival [9]. Another advantage is the postponing of systemic treatment and, consequently, the accompanying side effects and financial burden, while keeping the patient's quality-of-life unchanged. MDT can be achieved both by metastasectomy and stereotactic body radiotherapy (SBRT) [10,11]. Compared to conventional radiotherapy, SBRT is delivered as a large dose in a few fractions, resulting in a high biological effective dose. Dosage is conformal around the target with a rapid fall-off doses away from the target to minimise the effect on the surrounding tissue [12]. For non-cranial metastases of the prostate and bladder, a total of three fractions of $10 \mathrm{~Gy}$ is prescribed, which can be reduced to three fractions of 9, 8 or $7 \mathrm{~Gy}$ if needed to respect the dose constraints to the surrounding organs of risk. For mRCC, a higher dosage of three times $14 \mathrm{~Gy}$ is attempted. An example of a radiation treatment planning can be found in Figure 1.

The use of MDT in treating oligometastatic RCC, bladder/urothelial cancer (UC), and prostate cancer (PCa) is gaining interest and popularity. In this topical review, we summarise the existing evidence of the treatment with MDT in these tumour types and give an overview of ongoing trials that may change the treatment paradigm for these patients in the future.

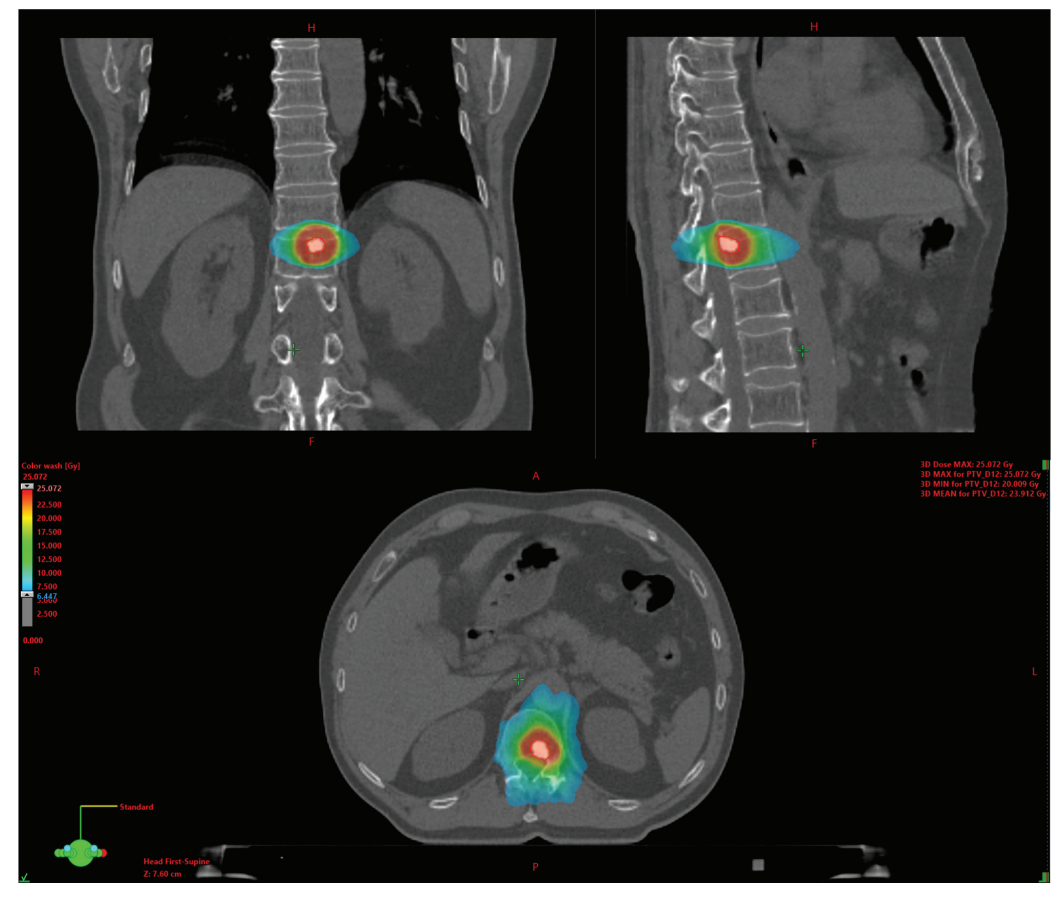

Figure 1. Example of a stereotactic body radiation therapy (SBRT) planning on a metastatic bone lesion. 


\section{Renal cancer}

RCC represents 3\%-5\% of adult cancers and accounts for more than 330,000 cases per year worldwide [13]. Up to 20\% of patients have upfront metastatic disease and about $20 \%-40 \%$ of non-metastatic RCC patients will eventually develop metastasis, typically located in the lung, liver, bones and brain [14, 15]. Standard management for mRCC is based on ICI and/or targeted therapy [16]. Close active surveillance with deferred systemic treatment can be proposed in case of asymptomatic patients with limited disease burden. Before the availability of tyrosine kinase inhibitors and $\mathrm{ICl}$, the prognosis of $\mathrm{mRCC}$ patients was poor with a median survival time ranging from 6 to 12 months, and even lower in case of brain metastases [17, 18]. However, currently a median OS up to 33 months has been reported [7]. Patients developing metachronous $\mathrm{mRCC}$ perform better than those presenting with synchronous $\mathrm{mRCC}$ [19].

While in the era of treatment with cytokines cytoreductive nephrectomy (CN) provided an OS benefit in the selected patients [17, 20], the role of $\mathrm{CN}$ needs to be re-established in the current era of immunotherapy and/or targeted therapy [20]. Multiple retrospective studies [22, 23] pointed towards an OS benefit for $\mathrm{CN}$; however, the randomised trial CARMENA [24] demonstrated non-inferior OS when sunitinib alone was compared to $\mathrm{CN}$ followed by sunitinib in patients presenting with intermediate or poor-risk disease. Good performance status and good/intermediate International Metastatic Renal Cell Carcinoma Database Consortium and the Memorial Sloan Kettering Cancer Center risk classification were predictive for OS benefit with $\mathrm{CN}$, suggesting that this subgroup of patients might still benefit from upfront $\mathrm{CN}$. A second randomised trial (SURTIME [25]) was closed early due to poor accrual. In this trial, however, a trend towards an OS benefit was observed with $\mathrm{CN}$ performed in the absence of progression after 3 months of sunitinib, compared to immediate $\mathrm{CN}$ followed by sunitinib therapy. Until now, there are no prospective data on the combination of $\mathrm{CN}$ and immunotherapy. In a systematic review, it was stated that 13-30\% of patients receiving upfront $\mathrm{CN}$ do not proceed to systemic therapy due to rapid disease progression or complications. Therefore, they concluded that upfront $\mathrm{CN}$ should be reserved for $\mathrm{mRCC}$ patients with only limited metastatic burden amenable to surveillance or metastasectomy, for the use of palliation or in patients with a favourable response or stable disease after initial systemic treatment [20]. Stereotactic body radiotherapy (SBRT) might be an alternative to $\mathrm{CN}$ in non-operable mRCC patients [26-28] with further prospective studies ongoing $[14,29]$.

In oligometastatic RCC, the distinction between synchronous and metachronous metastases is important. In case of synchronous oligometastatic disease, a multimodality treatment using a combination of $\mathrm{CN}$, metastasectomy and systemic therapy might improve outcome in well-selected patients [30]. The prognosis of patients presenting with metachronous oligometastatic disease is better than those presenting with synchronous metastases, with time to development of the oligometastasis being an important prognostic factor [31-33]. Multiple retrospective studies demonstrated an improved survival using MDT for metachronous oligometastatic progression [34]. This knowledge, however, is not new. Two decades ago, Kavolius et al [35] reported long-term disease-free survival rates when metastasectomy was performed in patients presenting with oligometastatic RCC. The strongest predictors for prolonged survival are interval from nephrectomy to detection of metastasis, a single site of first recurrence, a solitary site of first metastasis, curative resection of first metastasis, and a metachronous presentation with recurrence $[33,35]$. The surgery has been performed for metastases in different organs, such as lung, bone (isolated metastasis), brain, liver, adrenal gland, thyroid and pancreas [36-47]. After receiving a metastasectomy with complete resection, the 5-year survival benefit is $45 \%$ [16].

Besides metastasectomy, radiotherapy can be used for treating oligometastatic RCC [15]. Initially, radiation was expected to be less efficient as RCC metastasis are known to be radio-resistant. As much as this is the case for conventional radiotherapy, it holds no truth when considering SBRT. SBRT delivers a very high biological dose in a low number of fractions, resulting in a high dose per fraction. As a consequence, the cell membrane is the target (and no longer the cancer cell DNA itself). The stimulation of the ceramide pathway eventually leads to endothelial damage and tumour cell kill [48]. As an extra advantage, SBRT is able to stimulate the immune system [34, 49]. Different retrospective trials showed a good local control (90\%-98\%) with low toxicity. These studies emphasised the power of SBRT to postpone the need for systemic treatment [15, 50-56], with comparable results to surgery [57]. Both intracranial radiosurgery and extracranial SBRT appeared to be very well tolerated. Fit patients with extracranial metastasis treated after an initial period of deferring systemic treatment had the best prognosis [57]. There are only few prospective trials available [58].A dose response relationship using SBRT has been suggested, with improved local control rates with delivery of a higher biologically effective dose[59]. 
There is currently no evidence to combine MDT with systemic treatment. Close surveillance is the recommended strategy after performing MDT. Trials investigating the combination of both SBRT and metastasectomy and checkpoint inhibitor immunotherapy are currently recruiting patients (Keynote 564, NCT01896271, NCT03065179, NCT02781506, NCT02855203, NCT03050060, NCT02318771, NCT02599779, NCT03149159, NCT02864615, NCT03469713 and NCT03226236). As RCC is considered an immunogenic tumour, the use of SBRT in the oligometastatic setting and the combination with immune therapy is particularly relevant. SBRT is considered to have an immunostimulating effect by converting immunologically cold tumours into hot tumours due to the combination of different mechanisms that increase tumour immunogenicity, overcome an immunosuppressive tumour microenvironment and recruit antigen-presenting and immune-effector cells to the tumour microenvironment [34]. This immunostimulating effect can also translate in the so-called abscopal effect, defined as the presence of an anti-tumour effect both inside and outside irradiation fields $[34,49,60]$. In the future, the use of biomarkers will be increasingly more important, as they can identify biological factors that may further improve patient selection.

Further prospective trials are needed to establish the role of SBRT or metastasectomy in metastatic RCC and to optimise the sequencing and combination of all treatment options in the era of targeted agents and immunomodulatory agents, and to identify the patients that will benefit the most from this approach.

\section{Urothelial bladder cancer}

Bladder cancer accounts for over 430,000 new cases worldwide every year [61, 62], with urothelial carcinoma (UC) being the predominant histological subtype in more than $90 \%$ of the diagnoses [61]). About $25 \%$ of the bladder cancers present with muscle-invasive disease [63] with a high ability to metastasise [64]. Approximately $5 \%$ of patients presents with upfront metastatic disease [65]. The prognosis of metastatic bladder cancer is poor, with a 5 -year overall survival (OS) rate of only $15 \%$.

Despite the bad prognosis of metastatic UC ( $\mathrm{mUC}$ ), a subgroup of patients lives longer than 5 years after diagnosis. This subgroup consists of oligometastatic patients presenting with $\leq 3$ metastatic lesions in a single organ (but no liver), and with the largest diameter of metastatic foci of $\leq 5 \mathrm{~cm}$ [66]. The critical question remains the definition of the imaging tool to optimise the finding of oligometastatic disease. Although fluorodeoxyglucose-positron emission tomography (PET)-computed tomography (CT) shows promising specificity and sensitivity, only small trials exist, and therefore it use remains controversial [64]).

MDT for mUC has been described in single-institution, small retrospective case series or observational reports [64]. Mostly, metastasectomy or SBRT was performed after platinum-based chemotherapy with only few reports on upfront metastasectomy [67]. A systematic review and meta-analysis reporting on 15 retrospective and 2 prospective trials, reported on metastasectomy in mUC [68]. Six of the studies included metastasectomy for different metastatic localisations, three studies reported on distant lymphadenectomy, five involved pulmonary metastasectomy and three reported on the resection of intracranial lesions. Lung metastases were the most common site of metastasectomy. Mean time to clinical relapse was 14 months and the overall survival from the resection of metastases reported in the different articles ranged from 2 to 60 months. Best results were observed in patients with a good response after chemotherapy (at least stable disease), in patients presenting with limited or solitary sites of metastases, and in patients presenting with the lymph node or lung metastases [68].

Shah et al [69] reported on the results of consolidating radiation therapy delivered to patients presenting with mUC after they received chemotherapy [69]). Of note, patient selection was highly selective as only 2 out of 22 patients had M1 disease (1 lung metastasis and 1 mediastinal lymphadenopathy). The remaining patients had N1-N3 disease. Median OS was 49 months with $36 \%$ of patients being disease-free after 6 years [69]). Manig et al [70] reported on the prognostic factors for survival in 63 patients with irradiated mUC [70]. Median overall survival after irradiation was 6 months. A radiation dose ( $<=20$ Gy equivalent dose in $2 \mathrm{~Gy}$ fractions or EQD2) was the only significant factor in multivariate analysis negatively influencing overall survival. In another retrospective cohort by Augugliaro, 13 patients with 21 lesions were treated with SBRT or three-dimensional conformal radiation therapy (3D-CRT) for recurrent oligometastatic transitional cell carcinoma with lymph node, bone and lung lesions or local recurrence [71]. Radiological progression of disease was registered in nine patients at the median of 4.2 months (range 1.9-18.8). Leonetti et al [72] retrospectively identified seven patients who were treated with SBRT for nodal metastasis 
(14 lesions) with the aim of either to consolidate the response achieved by a previous systemic therapy or to delay the start of systemic chemotherapy. Five patients had bladder UC, two patients had upper tract UC. The treatment was atoxic. They reported a progression-free survival (PFS) of 2.9 months $(95 \% \mathrm{Cl} 2.6-3.1)$ and median lesion progression-free survival, defined as local progression of the treated lesion, independently from the onset of new metastatic lesions, of 11.4 months ( $95 \% \mathrm{Cl} 3.4-19.4$ ).

Based on these clinical results, guidelines have incorporated MDT as a treatment option in a highly selected group of oligometastatic patients [65].

Additionally, the combination of SBRT and ICI holds promise. A synergistic effect of this combination has been demonstrated in preclinical trials [73]. However, from a clinical viewpoint, we have to await results on toxicity and efficacy. A phase 1 trial with nine patients demonstrated that the combination of SBRT and pembrolizumab was safe (grade 3 toxicity in 1 patient, no dose limiting events). When SBRT was administered before the 3th cycle of pembrolizumab, the response of non-irradiated lesions was clearly better than when SBRT was administered before the start of pembrolizumab. From this study, one can assume that the abscopal effect is more likely to happen when SBRT and pembrolizumab are delivered concomitantly [74]). In this setting, several trials are ongoing. A clinical registry (NCT02170181), 5,000 patients will be enrolled who will receive SBRT with the aim to define patterns of care. Another trial is looking at the feasibility of pembrolizumab and SBRT in patients with advanced, platinum-refractory urothelial carcinoma (NCT03287050). CHEERS (NCT03511391) is a randomised controlled phase II trial investigating whether the addition of SBRT to ICl can improve progression-free survival as compared to ICI monotherapy. The combination of radiation therapy and $\mathrm{ICI}$ is currently also being investigated in the setting of locally advanced urothelial carcinoma of the bladder (RACE IT trial, NCT03529890). Another phase 2 trial is evaluating the use of radiation therapy and durvalumab with or without tremelimumab for the patients with bladder cancer that cannot be removed by surgery, has spread to nearby tissue or lymph nodes, or metastatic bladder cancer (NCT03601455).

\section{Prostate cancer}

PCa is known to be a very heterogeneous disease, ranging from indolent and localised disease requiring only active surveillance or local treatment, to an aggressive type with high metastatic potential requiring multimodality treatment. Although approximately $80-85 \%$ of all prostate cancers are detected in a curable state, PCa still remains one of the leading causes of cancer-related mortality worldwide due to its high incidence [11]. Approximately $17 \%$ of patients with non-metastatic high-risk disease will develop metastases within 10 years after diagnosis [75] and about 4\% of all new prostate cancer diagnoses contain upfront metastatic disease [76]. PCa can spread lymphogeneous and hematogenous with bone, lung and liver being the most frequent sites of distant metastases [77]. The presence of visceral metastatic lesions worsens prognosis [78]. The standard of care for metastatic hormone-sensitive prostate cancer consists of androgen-deprivation therapy (ADT) [79], whether or not combined with second-line hormonal treatment or chemotherapy in de-novo metastasised disease. Although a response is observed in $80 \%-90 \%$, the majority of patients progresses to castration-refractory prostate cancer (CRPC) within $2-3$ years [ 80 , 81]. The median survival of these patients runs up to 35 months [82-84].

New insights have led to an improved understanding of the underlying mechanism of prostate carcinogenesis and metastasis and the contribution of tumour microenvironment in the metastatic process [85]. The increasing availability of imaging modalities as choline PET-CT and especially prostate-specific membrane antigen (PSMA) PET-CT empower the earlier detection of a single or a limited number of metastases

[86] and consequently increase the incidence of oligometastatic prostate cancer. There exist more than 35 retrospective case series and single-institution reports $[2,87]$ reporting on oligometastatic prostate cancer and treatment with MDT, strengthened by several prospective randomised controlled trials [88-90].

Within oligometastatic prostate cancer, we define three different subsections: upfront oligometastatic disease, oligorecurrent prostate cancer and oligoprogression in CRPC. 


\section{Upfront oligometastatic disease (hormone sensitive)}

In de novo metastatic disease, ADT remains the cornerstone treatment [91]. Recent randomised trials demonstrated improved overall survival when chemotherapy or second-line androgen receptor target agents were added to ADT.

In case of low-volume metastatic disease, 3-year OS significantly increased from $73 \%$ to $81 \%$ when radiotherapy to the prostate (and consequently primary tumour) was added to ADT [92]. This benefit was also suggested in the HORRAD trial [93] which demonstrated, although not significant, an OS benefit with a hazard ratio similar to the STAMPEDE trial (HR 0.68, 95\% CI 0.42 -1.10 and hazard ratio $0.68 ; 95 \% \mathrm{Cl} 0.52-0.90$ respectively). The lack of significance is probably due to the fact that the trial was underpowered to be able to demonstrate a difference in the low-volume subgroup. Pooled data of HORRAD and STAMPEDE showed a 7\% improvement in 3-year survival in men with fewer than five bone metastases [94]. Concerning radical prostatectomy as the treatment of the primary in this setting, only retrospective data exist [95-100]. However multiple trials are ongoing (NCT01957436 PEACE 1, NCT03988686, NCT01751438, NCT02454543, g-RAMPP and ISRCTN15704862 trombone). There are currently no data available on the combination of the treatment of the primary with abiraterone or enzalutamide, and only $18 \%$ of patients in the STAMPEDE trial received additional docetaxel. The PEACE-1 trial will address this issue (NCT01957436).

Few data exist on radical treatment for upfront oligometastatic PCa. In a small single-institution series, patients with upfront oligometastatic disease were treated with radiotherapy to the primary and to all bone metastasis in 18 out of 22 patients. Twelve out of 22 patients showed a clinical failure after a median of 23.6 months (15.3-106.1) from the start of ADT, while three patients became CRPC with a median time to castration resistance of 31 months. Prostate RT in oligometastatic patients was considered to be safe and to be able to offer long-lasting control [101]. Another single-institutional study retrospectively evaluated newly diagnosed prostate cancer with oligometastatic disease treated with a combination of HDR brachytherapy, MDT and ADT (36 months). 18 patients had a median follow-up time of 62.5 months, of which 16 patients experienced CRPC and 5 patients died of prostate cancer during follow-up. The 5-yr CRPC-FS and CSS was $64.4 \%$ and $87.9 \%$, respectively [102].

A prospective phase 2 trial (NCT03298087) is currently investigating the role of MDT in patients with newly-diagnosed M1a/b prostate cancer, with 1-5 lesions (excluding pelvic lymph nodes) based on PSMA PET-CT imaging. Patients will receive local treatment with radical prostatectomy, limited duration systemic therapy for a total of six months (leuprolide, abiraterone acetate with prednisone and apalutamide), metastasis-directed SBRT and post-operative fractionated radiotherapy if one of the following features is present on the prostatectomy specimen: $\mathrm{pT} \geq 3 \mathrm{a}$, (p)N1, or positive margins [103]. Primary endpoint is the percentage of patients achieving a serum PSA of < $0.05 \mathrm{ng} / \mathrm{mL}, 6$ months after recovery of serum testosterone $\geq 150 \mathrm{ng} / \mathrm{dL}$. The study aims at including 28 patients, with expected study completion date mid2023. In a trial by John Hopkins (NCT02716974), the safety (grades 3-5 toxicity evaluation) of oligometastatic-treatment with neo-adjuvant ADT and chemotherapy up to 6 months, followed by local tumour control with prostatectomy +/- adjuvant radiotherapy and consolidative SBRT to oligometastatic lesions, will be evaluated. The new arm of the STAMPEDE trial will investigate the role of the addition of MDT for oligometastatic lesions in addition to surgery or radiotherapy to the prostate and androgen deprivation therapy (STAMPEDE arm M).

\section{Oligorecurrence}

Approximately $17 \%$ of patients with high-risk local disease will eventually develop metastases within 10 years after diagnosis [75]. Guidelines consider ADT to be the treatment of choice in symptomatic patients. However, these guidelines approve the deferral of ADT being in case of asymptomatic patients with a PSA $<50 \mathrm{ng} / \mathrm{dL}$ and a PSA doubling time of more than 12 months [104]. Novel imaging techniques such as choline PET-CT and certainly PSMA PET-CT have led to an increased and earlier diagnosis of metastatic lesions. There is evidence that $75 \%$ of patients with recurrence after primary therapy will have $\leq 3$ involved metastatic sites [87]. This situation is termed oligorecurrent $\mathrm{PCa}$ and is defined as the development of a limited number of metastatic lesions after primary treatment with radical prostatectomy and/ or radiotherapy (RT). Multiple retrospective trials have been published that address the feasibility, low toxicity rates and promising outcome of MDT in those patients. It has been shown that about $50 \%$ of patients are progression-free at 1-3 years, when treated with MDT on the oligorecurrent lesions [105]. 
The prospective phase II trial STOMP [88] compared MDT with surveillance with ADT-free survival as primary endpoint. In total, 62 patients with three or less oligorecurrent choline PET-CT detected lesions and primary controlled tumour were included. For a median follow-up time of 3 years (IQR 2.3-3.7 years), MDT resulted in a 10 months ADT-free survival benefit compared to the surveillance arm. There was no grade $>1$ toxicity. These findings were confirmed by the POPSTAR trial [89] that evaluated the feasibility and tolerability of patients with oligorecurrent prostate cancer being treated with single-fraction SBRT, with $97 \%$ of the patients receiving the prescribed treatment. This treatment was well tolerated with one patient developing grade 3 toxicity. In another prospective single-centre study [106], 57 patients were treated with SBRT for up to 3 PSMA-PET-confirmed oligometastases, with LN-only and bone-only disease in 37 (65\%) and 18 (31\%) patients, respectively. For a median follow-up of 16 months, this approach resulted in a median biochemical disease-free survival of 11 months, with $32 \%$ of the patients being free of biochemical failure (BF) at 15 months. All patients with BF $(n=43)$ underwent a subsequent PSMA-PET scan, which revealed no in-field failures. Nodal metastases tended to relapse in distant nodes and bone metastasis to other bony sites, with only 8 out of 43 failures being solitary for which repeat SBRT could be given. Recurrences to pelvic lymph nodes were generally considered for whole-pelvis RT and ADT instead of repeat SBRT [106]. Bowden et al [90] extended the number of lesions up to 5, in a large single-arm prospective trial, including 199 patients receiving SBRT. For a median follow-up time of 35.1 months, the median treatment escalation freesurvival was 27.1 months.

Another prospective phase 2 trial ORIOLE trial (NCT02680587) randomised between observation versus stereotactic ablative radiation (SABR) for patients with 1-3 metastatic lesions on conventional imaging with a PSAdt <15 months, with first results presented at ASTRO 2019. SABR significantly improved PFS with a hazard ratio of $0.3(95 \% \mathrm{Cl} 0.1-0.8)$ and appeared to be safe and well tolerated, with no grade 3 or higher adverse events identified. In this trial, a blinded PSMA PET-CT was performed at baseline and day 180, and those patients who received SABRT had variable coverage of occult PSMA radiotracer-avid lesions. Total consolidation of those lesions decreased the incidence of new metastases at 6 months [107].

Evidence for improvement in harder endpoints like OS was shown in the phase 2 trial SABR-COMET trial [9]. This randomised basket-trial included patients of different primary tumour origins, of which 16 (27\%) Pca, and showed a significant effect on both PFS and OS outcome when oligometastatic lesions (defined as 1-5 metastatic lesions and controlled primary, $n=14$ ) were treated with MDT, compared to palliative standard of care alone.

\section{Oligoprogression in castration-refractory prostate cancer}

In patients treated with ADT, the sensitivity to castration will eventually disappear due to the out-selection of castration-resistant clones, leading to the CRPC state of disease. CRPC is defined as the biochemical and/or radiological progression while castrate serum testosterone is $<50 \mathrm{ng} / \mathrm{dL}$ or $1.7 \mathrm{nmol} / \mathrm{L}$ [108]. The indefinite continuation of ADT in the CRPC setting is generally accepted, as two trials showed a survival benefit when ADT was sustained $[109,110]$. Moreover, the reimbursement of all subsequent treatments depends on the testosterone castrate level.

State-of-the art treatment consists of docetaxel [111-113], ARTA both in pre- [114, 115] and in post-docetaxel [116, 117] setting, cabazitaxel [118] or radium-223 [119], while ADT is continued. Trials with treatment with 177-luthetium are ongoing, with very promising first results $[120,121]$.

Nevertheless, CRPC is considered to be a very heterogeneous disease, with many details on tumour cell biology yet to be discovered. A subgroup of patients presenting with oligoprogressive disease defined as the progression of a limited number of lesions while other metastatic lesions are controlled by the current systemic treatment, has been described, [1-3, 122]. These progressive lesions are thought to contain clonogens resistant to the ongoing systemic treatment. Therefore, an approach with MDT to these lesions (also referred to as PDT: progression-directed therapy to include progression of the primary tumour and/or local recurrence) might keep patients responsive to their ongoing systemic treatment. Consequently, the need for next-systemic treatment (NEST) might be delayed, thereby also delaying at least its potential side effects and financial costs. There are currently very few prospective data on this novel approach. However, published retrospective trials show a fairly impressive postponement of NEST. Our own research group reported on 30 patients being treated with PDT for oligoprogressive lesions, showing a PFS of 11 months, and a NEST-FS of 21 months [122]. Those data correspond to the findings of Triggiani et al [123]. Others have investigated oligoprogression both in CSPC and CRPC patients [124-130], with only limited information available on the CRPC 
patients. A case report demonstrated the potential of SBRT as an additional tool in long-term control of oligoprogressive disease in CRPC, while the systemic therapy could be preserved [131]. Tran et al [132] showed early prospective results with 30\% 1-year NEST-FS in 17 CRPC patients. Yoshida reported on 23 patients receiving PDT for oligometastatic CRPC (1-3 lesions defined on whole-body diffusion-weighted magnetic resonance imaging, showing a PSA-response in 16 of 18 patients with intrapelvic recurrence and none in five patients with recurrence outside the pelvis. They conclude that PDT can be an effective treatment option and site localisation is an important factor [133]. A multicentre study investigated the role of MDT in 86 patients presenting with 1-5 oligoprogressive lesions (117 in total) [134]. Median distant progression-free survival after SBRT was 12.3 months (95\% Cl 5.5-19.1 months). One- and two-year distant progression-free survival was $52.3 \%$ and $33.7 \%$, respectively. There was a median NEST-FS of 21.8 months ( $95 \% \mathrm{Cl} 17.8-25.8$ months). In the University Hospitals of Leuven, a phase 2 trial will open soon (MEDCARE). Other prospective trials are ongoing to investigate the role of SBRT for oligometastatic CRPC (NCT02192788, NCT02759783, NCT02816983, NCT01859221 and NCT03644303) and others look specifically at the combination of SBRT and ARTA (NCT03449719 and NCT02685397)

\section{Conclusion}

We reviewed the results of MDT of oligometastatic disease in renal, bladder and prostate cancer. It is a promising treatment, which can postpone systemic treatment for a substantial time without inducing toxicity. Where the costs of new systemic treatments reach several thousands of euros per month per patient with continuous use, the price of MDT will be around 4,000 euro for the total treatment in case of SBRT. Furthermore, as the treatment options are limited, next line treatment can be 'saved' for later on. It is important that the discussion for MDT is based on a multidisciplinary decision to select for the appropriate treatment, and physicians create time to discuss this approach and the rationale with their patients. New data are awaited and further investigations will clarify the potential of this more aggressive treatment approach. We look forward to the day that MDT for oligometastatic disease in urological cancer will, finally, become second-hand news.

\section{Conflicts of interest}

The authors have no conflicts of interest.

\section{Funding}

None.

\section{References}

1. Conti Allesandro, D'Elia Carolina, and Cheng Monica, et al (2017) Oligometastases in genitourinary tumors: recent insights and future molecular diagnostic approach Eur Urol Suppl (16) 309-315

2. Weichselbaum RR and Hellman S (2011) Oligometastases revisited Nat Rev Clin Oncol 8(6) 378-382 https://doi.org/10.1038/nrclinonc.2011.44 PMID: 21423255

3. Singh D, Yi WS, and Brasacchio RA, et al (2004) Is there a favorable subset of patients with prostate cancer who develop oligometastases? Int J Radiat Oncol Biol Phys 58(1) 3-10 https://doi.org/10.1016/S0360-3016(03)01442-1

4. Schweizer MT, Zhou XC, and Wang H, et al (2013) Metastasis-free survival is associated with overall survival in men with PSA-recurrent prostate cancer treated with deferred androgen deprivation therapy Ann Oncol 24(11) 2881-2886 https://doi.org/10.1093/annonc/ mdt335 PMID: 23946329 PMCID: 3888237 
5. Niibe Y and Hayakawa K (2010) Oligometastases and oligo-recurrence: The new era of cancer therapy Jpn J Clin Oncol 40(2) 107-111 https://doi.org/10.1093/jjco/hyp167 PMID: 20047860 PMCID: 2813545

6. Cheung P (2016) Stereotactic body radiotherapy for oligoprogressive cancer Br J Radiol 89(1066) 20160251 https://doi.org/10.1259/ bjr.20160251 PMID: 27556349 PMCID: 5124800

7. Motzer RJ, Tannir NM, and McDermott DF, et al (2018) Nivolumab plus Ipilimumab versus Sunitinib in advanced renal-cell carcinoma N Engl J Med 378(14) 1277-1290 https://doi.org/10.1056/NEJMoa1712126 PMID: 29562145 PMCID: 5972549

8. Gundem G, Van Loo P, and Kremeyer B, et al (2105) The evolutionary history of lethal metastatic prostate cancer Nature 520(7547) 353-357 https://doi.org/10.1038/nature14347

9. Palma DA, Olson R, and Harrow S, et al (2019) Stereotactic ablative radiotherapy versus standard of care palliative treatment in patients with oligometastatic cancers (SABR-COMET): a randomised, phase 2, open-label trial Lancet 393(10185) 2051-2058 https://doi. org/10.1016/S0140-6736(18)32487-5 PMID: 30982687

10. Berkovic P, De Meerleer G, and Delrue L, et al (2013) Salvage stereotactic body radiotherapy for patients with limited prostate cancer metastases: deferring androgen deprivation therapy Clin Genitourin Cancer 11(1) 27-32 https://doi.org/10.1016/j.clgc.2012.08.003

11. Malik NH, Keilty DM, and Louie AV (2019) Stereotactic ablative radiotherapy versus metastasectomy for pulmonary metastases: guiding treatment in the oligometastatic era J Thorac Dis 11 S1333-S1335 https://doi.org/10.21037/jtd.2019.04.16 PMID: 31245125 PMCID: 6560524

12. Benedict SH, Yenice KM, and Followill D, et al Stereotactic body radiation therapy: the report of AAPM Tast Group 101 Med Phys 37(8) 4078-4101 PMID: 20879569

13. Bray F, Ferlay J, and Soerjomataram I, et al (2018) Global cancer statistics 2018: GLOBOCAN estimates of incidence and mortality worldwide for 36 cancers in 185 countries CA Cancer J Clin 68(6) 394-424 https://doi.org/10.3322/caac.21492 PMID: 30207593

14. Rühle A, Andratschke N, and Siva S, et al (2019) Is there a role for stereotactic radiotherapy in the treatment of renal cell carcinoma? Clin Transl Radiat Oncol 18 104-112 https://doi.org/10.1016/j.ctro.2019.04.012 PMID: 31341985 PMCID: 6630187

15. Meyer E, Pasquier D, and Bernadou G, et al (2018) Stereotactic radiation therapy in the strategy of treatment of metastatic renal cell carcinoma: a study of the Getug group Eur J Cancer 98 38-47 https://doi.org/10.1016/j.ejca.2018.04.008 PMID: 29864737

16. Loh J, Davis ID, and Martin JM, et al (2014) Extracranial oligometastatic renal cell carcinoma: Current management and future directions Future Oncol 10 761-774 https://doi.org/10.2217/fon.14.40 PMID: 24799057

17. Flanigan RC, Salmon SE, and Blumenstein BA, et al (2001) Nephrectomy followed by interferon alfa-2b compared with interferon alfa2b alone for metastatic renal-cell cancer N Engl J Med 345(23) 1655-1659 https://doi.org/10.1056/NEJMoa003013

18. Decker DA, Decker V, Herskovic A, et al (1984) Brain metastases in patients with renal cell carcinoma: prognosis and treatment $J$ Clin Oncol (2) 169-173 https://doi.org/10.1200/JCO.1984.2.3.169 PMID: 6699668

19. Kim SH, Lee DE, and Park B, et al (2019) Survival of patients receiving systematic therapy for metachronous or synchronous metastatic renal cell carcinoma: A retrospective analysis BMC Cancer 19(1) https://doi.org/10.1186/s12885-019-5900-1

20. Mickisch GHJ, Garin A, and Van Poppel H, et al (2001) Radical nephrectomy plus interferon-alfa-based immunotherapy compared with interferon alfa alone in metastatic renal-cell carcinoma: a randomised trial Lancet 358(9286) 966-970 https://doi.org/10.1016/S01406736(01)06103-7 PMID: 11583750

21. Bhindi B, Abel EJ, and Albiges L, et al (2019) Systematic review of the role of cytoreductive nephrectomy in the targeted therapy era and beyond: an individualized approach to metastatic renal cell carcinoma Eur Urol 75 111-128 https://doi.org/10.1016/j. eururo.2018.09.016 
22. Hanna N, Sun M, and Meyer CP, et al (2016) Survival analyses of patients with metastatic renal cancer treated with targeted therapy with or without cytoreductive nephrectomy: a national cancer data base study J Clin Oncol 34(27) 3267-3275 https://doi.org/10.1200/ JCO.2016.66.7931 PMID: 27325852 PMCID: 5024547

23. Heng DYC, Wells JC, and Rini BI, et al (2014) Cytoreductive nephrectomy in patients with synchronous metastases from renal cell carcinoma: Results from the International Metastatic Renal Cell Carcinoma Database Consortium Eur Urol 66(4) 704-710 https://doi. org/10.1016/j.eururo.2014.05.034 PMID: 24931622

24. Méjean A, Ravaud A, and Thezenas S, et al (2018) Sunitinib alone or after nephrectomy in metastatic renal-cell carcinoma N Engl J Med 379(5) 417-427 https://doi.org/10.1056/NEJMoa1803675 PMID: 29860937

25. Bex A, Mulders $P$, and Jewett M, et al (2019) Comparison of immediate vs deferred cytoreductive nephrectomy in patients with synchronous metastatic renal cell carcinoma receiving sunitinib: the SURTIME Randomized Clinical Trial JAMA Oncol 5(2) 164-170 https:// doi.org/10.1001/jamaoncol.2018.5543 PMCID: 6439568

26. Correa RJM, Rodrigues GB, and Chen $\mathrm{H}$, et al (2018) Stereotactic ablative radiotherapy (SABR) for large renal tumors Am J Clin Oncol Cancer Clin Trials 41(6) 568-575 https://doi.org/10.1097/COC.0000000000000329

27. Correa RJM, Ahmad B, and Warner A, et al (2018) A prospective phase I dose-escalation trial of stereotactic ablative radiotherapy (SABR) as an alternative to cytoreductive nephrectomy for inoperable patients with metastatic renal cell carcinoma Radiat Oncol 13(1) 47 https://doi.org/10.1186/s13014-018-0992-3 PMID: 29558966 PMCID: 5859400

28. Siva S, Pham D, and Gill S, et al (2012) A systematic review of stereotactic radiotherapy ablation for primary renal cell carcinoma BJU Int 110 e737-e743 https://doi.org/10.1111/j.1464-410X.2012.11550.x PMID: 23107102

29. Francolini G, Detti B, and Ingrosso G, et al (2018) Stereotactic body radiation therapy (SBRT) on renal cell carcinoma, an overview of technical aspects, biological rationale and current literature Crit Rev Oncol Hematol 131 24-9 https://doi.org/10.1016/j.critrevonc.2018.08.010 PMID: 30293702

30. Bex, Axel, de Bruijn Roderick, and Noe Allen, et al (2017) Time to targeted therapy after cytoreductive nephrectomy (CN) and surveillance in patients with synchronous unresectable metastases of renal cell carcinoma (RCC) J Clin Oncol 34604 https://doi.org/10.1200/ jco.2016.34.2_suppl.604

31. Santoni M, Conti A, and Porta C, et al (2015) Sunitinib, pazopanib or sorafenib for the treatment of patients with late relapsing metastatic renal cell carcinoma J Urol 193(1) 41-47 https://doi.org/10.1016/j.juro.2014.07.011

32. Hofmann HS, Neef H, and Krohe K, et al (2005) Prognostic factors and survival after pulmonary resection of metastatic renal cell carcinoma Eur Urol 48(1) 77-82 https://doi.org/10.1016/j.eururo.2005.03.004 PMID: 15967255

33. Dabestani S, Marconi L, and Hofmann F, et al (2014) Local treatments for metastases of renal cell carcinoma: a systematic review Lancet Oncol 15 e549-e561 https://doi.org/10.1016/S1470-2045(14)70235-9 PMID: 25439697

34. Tselis N and Chatzikonstantinou G (2019) Treating the Chameleon: Radiotherapy in the management of Renal Cell Cancer Clin Transl Radiat Oncol 16 7-14 https://doi.org/10.1016/j.ctro.2019.01.007 PMID: 30886912 PMCID: 6403071

35. Kavolius JP, Mastorakos DP, and Pavlovich C, et al (1998) Resection of metastatic renal cell carcinoma J Clin Oncol 16(6) 2261-2266 https://doi.org/10.1200/JCO.1998.16.6.2261 PMID: 9626229

36. Alt AL, Boorjian SA, and Lohse CM, et al (2011) Survival after complete surgical resection of multiple metastases from renal cell carcinoma Cancer 117(13) 2873-2882 https://doi.org/10.1002/cncr.25836 PMID: 21692048

37. Yang JC, Abad J, and Sherry R (2006) Treatment of oligometastases after successful immunotherapy Semin Radiat Oncol 16(2) 131-135 https://doi.org/10.1016/j.semradonc.2005.12.008 PMID: 16564448

38. Karam JA, Rini BI, and Varella L, et al (2011) Metastasectomy after targeted therapy in patients with advanced renal cell carcinoma J Urol 185(2) 439-444 https://doi.org/10.1016/j.juro.2010.09.086 
39. Russo AE, Untch BR, and Kris MG, et al (2019) Adrenal metastasectomy in the presence and absence of extraadrenal metastatic disease Ann Surg 270(2) 373-377 https://doi.org/10.1097/SLA.0000000000002749

40. Kollender Y, Bickels J, and Price WM, et al (2000) Metastatic renal cell carcinoma of bone: indications and technique of surgical intervention J Urol 164(5) 1505-1508 https://doi.org/10.1016/S0022-5347(05)67016-4 PMID: 11025692

41. Lin PP, Mirza AN, and Lewis VO, et al (2007) Patient survival after surgery for osseous metastases from renal cell carcinoma J Bone Jt Surg - Ser A 89(8) 1794-1801 https://doi.org/10.2106/00004623-200708000-00018

42. Higuchi T, Yamamoto N, and Hayashi $K$, et al (2018) Long-term patient survival after the surgical treatment of bone and soft-tissue metastases from renal cell carcinoma Bone Joint J 100-B(9) 1241-1248 https://doi.org/10.1302/0301-620X.100B9.BJJ-2017-1163.R3 PMID: 30168767

43. Vickers MM, Al-Harbi H, and Choueiri TK, et al (2013) Prognostic factors of survival for patients with metastatic renal cell carcinoma with brain metastases treated with targeted therapy: results from the international metastatic renal cell carcinoma database consortium Clin Genitourin Cancer 11(3) 311-315 https://doi.org/10.1016/j.clgc.2013.04.012 PMID: 23684422

44. Stief CG, Jáhne J, and Hagemann JH, et al (1997) Surgery for metachronous solitary liver metastases of renal cell carcinoma J Urol 158(2) 375-377 https://doi.org/10.1016/S0022-5347(01)64483-5 PMID: 9224306

45. Alves A, Adam R, and Majno P, et al (2003) Hepatic resection for metastatic renal tumors: is it worthwhile? Ann Surg Oncol 10(6) 705710 https://doi.org/10.1245/ASO.2003.07.024 PMID: 12839857

46. Tanis PJ, Van Der Gaag NA, and Busch ORC, et al (2009) Systematic review of pancreatic surgery for metastatic renal cell carcinoma Br J Surg 96(6) 579-592 https://doi.org/10.1002/bjs.6606 PMID: 19434703

47. Schrodter S, Hakenberg OW, and Manseck A, et al (2002) Outcome of surgical treatment of isolated local recurrence after radical nephrectomy for renal cell carcinoma J Urol 167(4) 1630-1633 https://doi.org/10.1016/S0022-5347(05)65167-1 PMID: 11912377

48. De Meerleer G, Khoo V, and Escudier B, et al (2014) Radiotherapy for renal-cell carcinoma Lancet Oncol 15(4) e170-e177 https://doi. org/10.1016/S1470-2045(13)70569-2 PMID: 24694640

49. Formenti SC and Demaria S (2009) Systemic effects of local radiotherapy Lancet Oncol 10 718-726 https://doi.org/10.1016/S14702045(09)70082-8 PMID: 19573801 PMCID: 2782943

50. Kano H, lyer A, and Kondziolka D, et al (2011) Outcome predictors of gamma knife radiosurgery for renal cell carcinoma metastases Neurosurgery 69(6) 1232-1239 https://doi.org/10.1227/NEU.0b013e31822b2fdc PMID: 21716155

51. Wersäll PJ, Blomgren H, and Lax I, et al (2005) Extracranial stereotactic radiotherapy for primary and metastatic renal cell carcinoma Radiother Oncol 77(1) 88-95 https://doi.org/10.1016/j.radonc.2005.03.022 PMID: 15972239

52. Ranck MC, Golden DW, and Corbin KS, et al (2013) Stereotactic body radiotherapy for the treatment of oligometastatic renal cell carcinoma Am J Clin Oncol Cancer Clin Trials 36(6) 589-595 https://doi.org/10.1097/COC.0b013e31825d52b2

53. Zelefsky MJ, Greco C, and Motzer R, et al (2012) Tumor control outcomes after hypofractionated and single-dose stereotactic imageguided intensity-modulated radiotherapy for extracranial metastases from renal cell carcinoma Int J Radiat Oncol Biol Phys 82(5) 17441748 https://doi.org/10.1016/j.ijrobp.2011.02.040

54. Ikushima H, Tokuuye $\mathrm{K}$, and Sumi M, et al (2000) Fractionated stereotactic radiotherapy of brain metastases from renal cell carcinoma Int J Radiat Oncol Biol Phys 48(5) 1389-1393 https://doi.org/10.1016/S0360-3016(00)00804-X PMID: 11121638

55. Cochran DC, Chan MD, and Aklilu M, et al (2012) The effect of targeted agents on outcomes in patients with brain metastases from renal cell carcinoma treated with Gamma Knife surgery: clinical article J Neurosurg 116(5) 978-983 https://doi.org/10.3171/2012.2.JNS111353 PMID: 22385005 PMCID: 3791504 
56. Franzese C, Franceschini D, and Di Brina L, et al (2019) Role of stereotactic body radiation therapy for the management of oligometastatic renal cell carcinoma J Urol 201(1) 70-75 https://doi.org/10.1016/j.juro.2018.08.049

57. Stenman M, Sinclair G, and Paavola P, et al (2018) Overall survival after stereotactic radiotherapy or surgical metastasectomy in oligometastatic renal cell carcinoma patients treated at two Swedish centres 2005-2014 Radiother Oncol 127(3) 501-506 https://doi. org/10.1016/j.radonc.2018.04.028 PMID: 29754859

58. Svedman C, Sandström P, and Pisa P, et al (2006) A prospective Phase II trial of using extracranial stereotactic radiotherapy in primary and metastatic renal cell carcinoma Acta Oncol 45(7) 870-875 https://doi.org/10.1080/02841860600954875 PMID: 16982552

59. Kothari G, Foroudi F, and Gill S, et al (2015) Outcomes of stereotactic radiotherapy for cranial and extracranial metastatic renal cell carcinoma: a systematic review Acta Oncol 54(2) 148-157 https://doi.org/10.3109/0284186X.2014.939298

60. Schaue D, Ratikan JA, and Iwamoto KS, et al (2012) Maximizing tumor immunity with fractionated radiation Int J Radiat Oncol Biol Phys 83(4) 1306-1310 https://doi.org/10.1016/j.ijrobp.2011.09.049 PMID: 22208977 PMCID: 3337972

61. Siegl RL and Miller KD JA (2019) Cancer statistics CA Cancer Clin J 69(1) 7-34

62. Antoni S, Ferlay J, and Soerjomataram I, et al (2017) Bladder cancer incidence and mortality: a global overview and recent trends Eur Urol 71 96-108 https://doi.org/10.1016/j.eururo.2016.06.010

63. Smith $A B$, Deal $A M$, and Woods ME, et al (2014) Muscle-invasive bladder cancer: evaluating treatment and survival in the National Cancer Data Base BJU Int 114(5) 719-726 https://doi.org/10.1111/bju.12601

64. Mertens LS and Horenblas S (2017) Bladder cancer: oligometastases and imaging Nat Rev Urol 14(9) 513-514 https://doi.org/10.1038/ nrurol.2017.96 PMID: 28631741

65. Flaig TW, Spiess TW, and Agarwal N, et al (2020) Bladder Cancer, Version 3.2020, NCCN Clinical Practice Guidelines in Oncology J Natl Compr Canc Netw 18(3) 329-354 https://doi.org/10.6004/jnccn.2020.0011

66. Ogihara K, Kikuchi E, and Watanabe K, et al (2017) Can urologists introduce the concept of "oligometastasis" for metastatic bladder cancer after total cystectomy? Oncotarget 8(67) 111819-111835 https://doi.org/10.18632/oncotarget.22911

67. Decaestecker K, Fonteyne V, and Oosterlinck W (2017) Perspective on cytoreduction and metastasis-directed therapy in node positive and metastatic urothelial carcinoma of the bladder Transl Androl Urol 6(6) 1117-1122 https://doi.org/10.21037/tau.2017.08.09

68. Patel V, Collazo Lorduy A, and Stern A, et al (2017) Survival after metastasectomy for metastatic urothelial carcinoma: a systematic review and meta-analysis BI Cancer 3(2) 121-132 https://doi.org/10.3233/BLC-170108 PMID: 28516157 PMCID: 5409038

69. Shah S, Zhang CA, and Hancock S, et al (2017) Consolidative radiotherapy in metastatic urothelial cancer Clin Genitourin Cancer 15(6) 685-688 https://doi.org/10.1016/j.clgc.2017.04.007 PMID: 28465049

70. Manig L, Käsmann L, and Janssen S, et al (2016) Predicting survival after irradiation of metastases from transitional carcinoma of the bladder Anticancer Res 36(12) 6663-6665 https://doi.org/10.21873/anticanres.11275 PMID: 27919999

71. Augugliaro M, Marvaso G, and Ciardo D, et al (2019) Recurrent oligometastatic transitional cell bladder carcinoma: is there room for radiotherapy? Neoplasma 66(1) 160-165 https://doi.org/10.4149/neo_2018_180522N333

72. Leonetti A, D'Abbiero N, and Baldari G, et al (2018) Radiotherapy for the treatment of distant nodes metastases from oligometastatic urothelial cancer: a retrospective case series Int J Urol 25(10) 879-886 https://doi.org/10.1111/iju.13773 PMID: 30103254

73. Herrera FG, Bourhis J, and Coukos G (2017) Radiotherapy combination opportunities leveraging immunity for the next oncology practice CA Cancer J Clin 67(1) 65-85 https://doi.org/10.3322/caac.21358

74. Sundahl N, Vandekerkhove G, and Decaestecker K, et al (2019) Randomized phase 1 trial of pembrolizumab with sequential versus concomitant stereotactic body radiotherapy in metastatic urothelial carcinoma Eur Urol 75(5) 707-711 https://doi.org/10.1016/j. eururo.2019.01.009 PMID: $\underline{30665814}$ 
75. Cooperberg MR, Broering JM, and Carroll PR (2009) Risk assessment for prostate cancer metastasis and mortality at the time of diagnosis J Natl Cancer Inst 101(12) 878-887 https://doi.org/10.1093/jnci/djp122 PMID: 19509351 PMCID: 2697208

76. Buzzoni C, Auvinen A, and Roobol MJ, et al (2015) Metastatic prostate cancer incidence and prostate-specific antigen testing: new insights from the European Randomized Study of Screening for Prostate Cancer Eur Urol 68(5) 885-890 https://doi.org/10.1016/j. eururo.2015.02.042 PMID: 25791513 PMCID: 4982869

77. Bubendorf L, Schöpfer A, and Wagner U, et al (2000) Metastatic patterns of prostate cancer: An autopsy study of 1,589 patients Hum Pathol 31(5) 578-583 https://doi.org/10.1053/hp.2000.6698 PMID: 10836297

78. Shou J, Zhang Q, and Wang S, et al (2018) The prognosis of different distant metastases pattern in prostate cancer: a population based retrospective study Prostate 78(7) 491-497 https://doi.org/10.1002/pros.23492 PMID: 29436722

79. Huggins $C$ and Hodges CV (1941) Studies on prostatic cancer i. the effect of castration, of estrogen and of androgen injection on serum phosphatases in metastatic carcinoma of the prostate Cancer Res 1(4) 293-297

80. Harris WP, Mostaghel EA, and Nelson PS, et al (2009) Androgen deprivation therapy: Progress in understanding mechanisms of resistance and optimizing androgen depletion Nat Clin Pract Urol 6(2) 76-85 https://doi.org/10.1038/ncpuro1296 PMID: 19198621 PMCID: 2981403

81. Chandrasekar T, Yang JC, and Gao AC, et al (2015) Mechanisms of resistance in castration-resistant prostate cancer (CRPC) Transl Androl Urol 4(3) 365-380

82. Yamashita S, Kohjimoto Y, and Iguchi T, et al (2016) Prognostic factors and risk stratification in patients with castration-resistant prostate cancer receiving docetaxel-based chemotherapy BMC Urol 16(1) https://doi.org/10.1186/s12894-016-0133-y PMID: 27001073 PMCID: 4802623

83. Miyazawa Y, Sekine Y, and Shimizu N, et al (2019) An exploratory retrospective multicenter study of prognostic factors in mCRPC patients undergoing enzalutamide treatment: Focus on early PSA decline and kinetics at time of progression Prostate 79(12) 14621470 https://doi.org/10.1002/pros.23865 PMID: 31334872

84. Halabi S, Lin C-Y, and Kelly WK, et al (2014) Updated prognostic model for predicting overall survival in first-line chemotherapy for patients with metastatic castration-resistant prostate cancer J Clin Oncol 32(7) 671-677 https://doi.org/10.1200/JCO.2013.52.3696 PMID: 24449231 PMCID: 3927736

85. Santoni M, Piva F, and Scarpelli M, et al (2015) The origin of prostate metastases: emerging insights Cancer Metastasis Rev 34(4) 765773 https://doi.org/10.1007/s10555-015-9597-6 PMID: 26363603

86. Ceci F, Herrmann K, and Hadaschik B, et al (2017) Therapy assessment in prostate cancer using choline and PSMA PET/CT Eur J Nucl Med Mol Imaging 44(Suppl1) 78-83 https://doi.org/10.1007/s00259-017-3723-3 PMID: 28540419

87. Foster CC, Weichselbaum RR, and Pitroda SP (2019) Oligometastatic prostate cancer: reality or figment of imagination? Cancer 125(3) 340-352 https://doi.org/10.1002/cncr.31860 PMCID: 6587458

88. Ost P, Reynders D, and Decaestecker K, et al (2018) Surveillance or metastasis-directed therapy for oligometastatic prostate cancer recurrence: a prospective, randomized, multicenter phase II trial J Clin Oncol 36(5) 446-453 https://doi.org/10.1200/JCO.2017.75.4853

89. Siva S, Bressel M, and Murphy DG, et al (2018) Stereotactic abative body radiotherapy (SABR) for oligometastatic prostate cancer: a prospective clinical trial Eur Urol 74(4) 455-462 https://doi.org/10.1016/j.eururo.2018.06.004 PMID: 30227924

90. Bowden P, See AW, and Frydenberg M, et al (2020) Fractionated stereotactic body radiotherapy for up to five prostate cancer oligometastases: interim outcomes of a prospective clinical trial Int J Cancer 146(1) 161-168 https://doi.org/10.1002/ijc.32509

91. Pagliarulo V, Bracarda S, and Eisenberger MA, et al (2012) Contemporary role of androgen deprivation therapy for prostate cancer Eur Urol 61 11-25 https://doi.org/10.1016/j.eururo.2011.08.026 PMCID: 3483081 
92. Parker CC, James ND, and Brawley CD, et al (2018) Radiotherapy to the primary tumour for newly diagnosed, metastatic prostate cancer (STAMPEDE): a randomised controlled phase 3 trial Lancet 392(10162) 2353-2366 https://doi.org/10.1016/S0140-6736(18)32486-3 PMID: 30355464 PMCID: 6269599

93. Boevé LMS, Hulshof MCCM, and Vis AN, et al (2019) Effect on survival of androgen deprivation therapy alone compared to androgen deprivation therapy combined with concurrent radiation therapy to the prostate in patients with primary bone metastatic prostate cancer in a Prospective Randomised Clinical Trial: data from the HORRAD Trial Eur Urol 75(3) 410-418 https://doi.org/10.1016/j. eururo.2018.09.008

94. Burdett S, Boevé LM, and Ingleby FC, et al (2019) Prostate radiotherapy for metastatic hormone-sensitive prostate cancer: a STOPCAP systematic review and meta-analysis Eur Urol 76(1) 115-124 https://doi.org/10.1016/j.eururo.2019.02.003 PMID: 30826218 PMCID: 6575150

95. Sooriakumaran P, Karnes J, and Stief C, et al (2016) A multi-institutional analysis of perioperative outcomes in 106 men who underwent radical prostatectomy for distant metastatic prostate cancer at presentation Eur Urol 69(5) 788-794 https://doi.org/10.1016/j. eururo.2015.05.023

96. Heidenreich A, Pfister D, and Porres D (2015) Cytoreductive radical prostatectomy in patients with prostate cancer and low volume skeletal metastases: results of a feasibility and case-control study J Urol 193(3) 832-838 https://doi.org/10.1016/j.juro.2014.09.089

97. Gratzke C, Engel J, and Stief CG (2014) Role of radical prostatectomy in metastatic prostate cancer: data from the munich cancer registry Eur Urol 66 602-603 https://doi.org/10.1016/j.eururo.2014.04.009 PMID: 24821581

98. Culp SH, Schellhammer PF, and Williams MB (2014) Might men diagnosed with metastatic prostate cancer benefit from definitive treatment of the primary tumor? A SEER-based study Eur Urol 65(6) 1058-1066 https://doi.org/10.1016/j.eururo.2013.11.012

99. Fossati N, Trinh QD, and Sammon J, et al (2015) Identifying optimal candidates for local treatment of the primary tumor among patients diagnosed with metastatic prostate cancer: a SEER-based study Eur Urol 67(1) 3-6 https://doi.org/10.1016/j.eururo.2014.08.056

100.Satkunasivam R, Kim AE, and Desai M, et al (2015) radical prostatectomy or external beam radiation therapy vs no local therapy for survival benefit in metastatic prostate cancer: a SEER-medicare analysis J Urol 194(2) 378-385 https://doi.org/10.1016/j.juro.2015.02.084 PMID: 25711194 PMCID: 4834920

101. Riva G, Marvaso G, and Augugliaro M, et al (2017) Cytoreductive prostate radiotherapy in oligometastatic prostate cancer: a single centre analysis of toxicity and clinical outcome Ecancermedicalscience 11786 https://doi.org/10.3332/ecancer.2017.786 PMID: 29225693 PMCID: 5718249

102. Tsumura H, Ishiyama H, and Tabata K-I, et al (2019) Long-term outcomes of combining prostate brachytherapy and metastasis-directed radiotherapy in newly diagnosed oligometastatic prostate cancer: a retrospective cohort study Prostate 79(5) 506-514 https://doi. org/10.1002/pros.23757

103.Parikh NR, Huiza C, and Patel JS, et al (2019) Systemic and tumor-directed therapy for oligometastatic prostate cancer: study protocol for a phase II trial for veterans with de novo oligometastatic disease BMC Cancer 19(1) 291 https://doi.org/10.1186/s12885-0195496-5 PMID: 30935383 PMCID: 6444674

104.Mottet N, Cornford P, and van den Bergh RCN, et al EAU Guidelines: Prostate Cancer, Uroweb [https://uroweb.org/guideline/prostatecancer/\#6]

105.Decaestecker K, De Meerleer G, and Lambert B, et al (2014) Repeated stereotactic body radiotherapy for oligometastatic prostate cancer recurrence Radiat Oncol 9(1) https://doi.org/10.1186/1748-717X-9-135 PMID: 24920079 PMCID: 4066290

106.Kneebone A, Hruby G, and Ainsworth H, et al (2018) stereotactic body radiotherapy for oligometastatic prostate cancer detected via prostate-specific membrane antigen positron emission tomography Eur Urol Oncol 1(6) 531-537 https://doi.org/10.1016/j. euo.2018.04.017 
107.Philips R, Lim SJ, and Shi WY, et al (2019) Primary outcomes of a phase II randomized trial of observation versus stereotactic ablative radiation for oligometastatic prostate cancer (ORIOLE) Int J Radiat Oncol Biol Phys 105(3) 681 https://doi.org/10.1016/j.ijrobp.2019.08.031

108.Cornford P, Bellmunt J, and Bolla M, et al (2017) EAU-ESTRO-SIOG guidelines on prostate cancer. part ii: treatment of relapsing, metastatic, and castration-resistant prostate cancer Eur Urol 71(4) 630-642 https://doi.org/10.1016/j.eururo.2016.08.002

109. Hussain M, Wolf M, and Marshall E, et al (1994) Effects of continued androgen-deprivation therapy and other prognostic factors on response and survival in phase II chemotherapy trials for hormone- refractory prostate cancer: a Southwest Oncology Group report J Clin Oncol 12(9) 1868-1875 https://doi.org/10.1200/JCO.1994.12.9.1868 PMID: 8083710

110. Taylor CD, Elson P, and Trump DL (1993) Importance of continued testicular suppression in hormone-refractory prostate cancer J Clin Oncol 11(11) 2167-2172 https://doi.org/10.1200/JC0.1993.11.11.2167 PMID: 8229130

111.Tannock IF, de Wit R, and Berry WR, et al (2004) Docetaxel plus prednisone or mitoxantrone plus prednisone for advanced prostate cancer N Engl J Med 351(15) 1502-1512 https://doi.org/10.1056/NEJMoa040720 PMID: 15470213

112.Beer TM, Garzotto M, and Henner WD, et al (2004) Multiple cycles of intermittent chemotherapy in metastatic androgen-independent prostate cancer Br J Cancer 91(8) 1425-1427 https://doi.org/10.1038/sj.bjc.6602198 PMID: 15467765 PMCID: 2409932

113.Ohlmann CH, Ozgur E, and Wille S, et al (2006) Second-line chemotherapy with docetaxel for prostatespecific antigen (PSA) relapse in men with hormonerefractory prostate cancer (HRPC) previously treated with docetaxel-based chemotherapy Eur Urol Suppl 5(2) 95 https://doi.org/10.1016/S1569-9056(06)60295-9

114.Ryan CJ, Smith MR, and Fizazi K, et al (2015) Abiraterone acetate plus prednisone versus placebo plus prednisone in chemotherapy-naive men with metastatic castration-resistant prostate cancer (COU-AA-302): final overall survival analysis of a randomised, double-blind, placebo-controlled phase 3 study Lancet Oncol 16(2) 152-160 https://doi.org/10.1016/S1470-2045(14)71205-7 PMID: 25601341

115.Froehner M and Wirth MP (2014) Enzalutamide in metastatic prostate cancer before chemotherapy N Engl J Med 371 1755-1756 https://doi.org/10.1056/NEJMc1410239 PMID: 25354112

116.Scher HI, Fizazi K, and Saad F, et al (2012) Increased survival with enzalutamide in prostate cancer after chemotherapy N Engl J Med 367(13) 1187-1197 https://doi.org/10.1056/NEJMoa1207506 PMID: 22894553

117.Fizazi K, Scher HI, and Molina A, et al (2012) Abiraterone acetate for treatment of metastatic castration-resistant prostate cancer: final overall survival analysis of the COU-AA-301 randomised, double-blind, placebo-controlled phase 3 study Lancet Oncol 13(10) 983-992 https://doi.org/10.1016/S1470-2045(12)70379-0 PMID: 22995653

118.De Bono JS, Oudard S, and Ozguroglu M, et al (2010) Prednisone plus cabazitaxel or mitoxantrone for metastatic castration-resistant prostate cancer progressing after docetaxel treatment: a randomised open-label trial Lancet 376(9747) 1147-1154 https://doi. org/10.1016/S0140-6736(10)61389-X PMID: 20888992

119.Parker C, Nilsson D, and Heinrich S, et al (2013) Alpha emitter radium-223 and survival in metastatic prostate cancer N Engl J Med 369(3) 213-223 https://doi.org/10.1056/NEJMoa1213755 PMID: 23863050

120.Aghdam RA, Amoui M, and Ghodsirad M, et al (2019) Efficacy and safety of 177Lutetium-prostate-specific membrane antigen therapy in metastatic castration-resistant prostate cancer patients: First experience in West Asia-a prospective study World J Nucl Med 18(3) 258-265 https://doi.org/10.4103/wjnm.WJNM_66_18 PMID: 31516369 PMCID: 6714159

121. Hofman MS, Violet J, and Hicks RJ, et al (2018) [ 177 Lu]-PSMA-617 radionuclide treatment in patients with metastatic castration-resistant prostate cancer (LuPSMA trial): a single-centre, single-arm, phase 2 study Lancet Oncol 19(6) 825-833 https://doi.org/10.1016/ S1470-2045(18)30198-0 PMID: 29752180

122.Berghen C, Joniau S, and Ost P, et al (2019) progression-directed therapy for oligoprogression in castration-refractory prostate cancer Eur Urol Oncol 23 S2588-9311(19)30138-5 
123. Triggiani L, Alongi F, and Buglione M, et al (2017) Efficacy of stereotactic body radiotherapy in oligorecurrent and in oligoprogressive prostate cancer: new evidence from a multicentric study Br J Cancer 116(12) 1520-1525 https://doi.org/10.1038/bjc.2017.103 PMID: 28449007 PMCID: $\underline{5518848}$

124. Muldermans JL, Romak LB, and Kwon ED, et al (2016) Stereotactic body radiation therapy for oligometastatic prostate cancer. Int J Radiat Oncol Biol Phys 95(2) 696-702 https://doi.org/10.1016/j.jijobp.2016.01.032 PMID: 27131082 PMCID: 5154616

125. Tabata KI, Niibe Y, and Satoh T, et al (2012) Radiotherapy for oligometastases and oligo-recurrence of bone in prostate cancer Pulm Med 2012541656 https://doi.org/10.1155/2012/541656 PMID: 22991663 PMCID: 3444052

126.Ahmed KA, Barney BM, and Davis BJ, et al (2013) Stereotactic body radiation therapy in the treatment of oligometastatic prostate cancer Front Oncol 2215 https://doi.org/10.3389/fonc.2012.00215 PMID: 23346551 PMCID: 3551203

127.Franzese C, Zucali PA, and Di Brina L, et al (2018) The efficacy of Stereotactic body radiation therapy and the impact of systemic treatments in oligometastatic patients from prostate cancer Cancer Med 7(9) 4379-4386 https://doi.org/10.1002/cam4.1707 PMID: 30073758 PMCID: 6144154

128. Kam TY, Chan OSH, and Hung AWM, et al (2019) Utilization of stereotactic ablative radiotherapy in oligometastatic \& oligoprogressive skeletal metastases: results and pattern of failure Asia Pac J Clin Oncol 15(Suppl 2) 14-19 https://doi.org/10.1111/ajco.13115

129.Deek MP, Yu C, and Phillips R, et al (2019) Radiation therapy in the definitive management of oligometastatic prostate cancer: the Johns Hopkins experience Int J Radiat Oncol Biol Phys 105(5) 948-956 https://doi.org/10.1016/j.ijrobp.2019.08.008 PMID: 31419509 PMCID: 7050213

130. Moyer CL, Phillips R, and Deek MP, et al (2019) Stereotactic ablative radiation therapy for oligometastatic prostate cancer delays timeto-next systemic treatment World J Urol 37(12) 2623-2629 https://doi.org/10.1007/s00345-018-2477-2

131. Nguyen T-C, Bajwa R, and Bari S, et al (2018) Stereotactic body radiation therapy for the treatment of oligoprogression on androgen receptor targeted therapy in castration-resistant prostate cancer Oxford Med Case Rep 2018(1) https://doi.org/10.1093/omcr/omx078

132.Tran PT, Leigh MC, and Ryan P, et al (2017) Stereotactic ablative radiation therapy for the treatment of oligometastatic prostate cancer J Clin Oncol 15(suppl_5020-5020)

133.Yoshida S, Takahara T, and Arita Y, et al (2019) Progressive site-directed therapy for castration-resistant prostate cancer: localization of the progressive site as a prognostic factor Int J Radiat Oncol Biol Phys 105(2) 376-381 https://doi.org/10.1016/j.ijrobp.2019.06.011 PMID: 31201896

134. Triggiani L, Mazzola R, and Magrini SM, et al (2019) Metastasis-directed stereotactic radiotherapy for oligoprogressive castrationresistant prostate cancer: a multicenter study World J Urol 37(12) 2631-2637 https://doi.org/10.1007/s00345-019-02717-7 PMID: 30859273 